\title{
A Novel Risk-Scoring Model for Prediction of Premalignant and Malignant Lesions of Uterine Endometrium Among Symptomatic Premenopausal Women
}

International Journal of Women's Health

\section{Sujatha Bagepalli Srinivas (iD Shruthi Sangamesh Kubakaddi Samatha Polisetti Shiny Amber Shyamala Guruvare Muralidhar Vaman Pai $(\mathbb{D}$ \\ Department of Obstetrics and Gynecology, Kasturba Medical College, Manipal Academy of Higher Education, Manipal, Karnataka, India}

Purpose: Uterine cancer is the second most prevalent cancer of the female genital tract, with $90 \%$ of it being of endometrial origin. The aim of this research was to create and validate a risk-scoring model using patients' clinical variables in predicting premalignant and malignant lesions of the uterine endometrium among premenopausal women with abnormal uterine bleeding (AUB).

Methods: This is a retrospective cohort study conducted at a tertiary hospital of Southern India for a period of 5 years from July 2014 to August 2019, including women aged $\leq 55$ years who had AUB and underwent endometrial biopsy. The incidence of atypical endometrial hyperplasia (AEH) and endometrial cancer (EC) was determined, and clinical and demographic variables were compared among cases (AEH/EC) and controls (no AEH/EC) using simple logistic regression. A risk-scoring model was derived and validated with a splitsample internal validation method.

Results: A total of 472 premenopausal women presenting with AUB were included in the study. There were 20 women (4.2\%) with AEH and eight $(1.7 \%)$ with EC. We found a statistically significant positive correlation of an anovulatory pattern of bleeding (odds ratio $[\mathrm{OR}]=3.4 ; p=0.009)$, age $\geq 45$ years $(\mathrm{OR}=1.12 ; p=0.01)$, body mass index (BMI) $\geq 30 \mathrm{~kg} / \mathrm{m}^{2}(\mathrm{OR}=2.46 ; p=0.04)$ and diabetes mellitus $(\mathrm{OR}=3.00 ; p=0.02)$ with a higher risk of $\mathrm{AEH} / \mathrm{EC}$ diagnosis upon histopathological examination of endometrial biopsy specimens of the study population. A risk-scoring model (PAD30) was created using these variables to predict premalignant and malignant endometrial lesions. The best cutoff score derived by the receiver operating characteristics (ROC) curve, of $\geq 5$, had a sensitivity of $85.7 \%$ and specificity of $87.6 \%$ with an area under the curve (AUC) of $0.84(95 \%$ CI $0.75-0.93 ; p=0.04)$. With a positive likelihood ratio of 6.91 , our prediction model increases the post-test probability of $\mathrm{AEH} / \mathrm{EC}$ to $30.6 \%$ from $6 \%$ of the pre-test probability.

Conclusion: The proposed model demonstrated a moderate diagnostic accuracy in predicting premalignant and malignant lesions of the uterine endometrium among symptomatic premenopausal women.

Keywords: premenopause, uterine cancer, malignancy, hyperplasia, risk model

\section{Introduction}

Uterine cancer is the second most prevalent cancer of the female genital tract, after cervical cancer. ${ }^{1}$ About $90 \%$ of uterine cancers are of endometrial origin. ${ }^{2}$ Endometrial hyperplasia is identified as a precursor to endometrial carcinoma,
Srinivas

Department of Obstetrics and Gynecology, Kasturba Medical College, Manipal Academy of Higher Education, Manipal 576104, Karnataka, India

Tel +91 8660778169

Fax + 91-820-2571927

Email bssujata@gmail.com
International Journal of Women's Health 2020:I2 883-89| 
especially with nuclear atypia. ${ }^{3}$ The risk of progression of endometrial hyperplasia without atypia is $<1-5 \%$ compared to $8-28 \%$ with the presence of nuclear atypia, and nearly $40 \%$ of cases diagnosed with atypical endometrial hyperplasia were known to have endometrial carcinoma in the hysterectomy specimen., ${ }^{4,5}$

The WHO 2014 classification of endometrial hyperplasia is more likely to identify precancerous lesions compared to the older classification of 1994. It has been designed to use modified pathological criteria for diagnosing premalignant lesions. ${ }^{4}$

In recent years, the incidence of endometrial cancer has been steadily increasing, along with an increased prevalence of obesity and lifestyle-related problems such as increasing incidences of nulliparity and infertility. ${ }^{6,7}$ Studies have clearly identified nulliparity, obesity, increasing age, diabetes and late-onset menopause as risk factors for endometrial cancer. ${ }^{8-11}$

About $90 \%$ of patients with endometrial hyperplasia or endometrial carcinoma have abnormal uterine bleeding (AUB) as the predominant symptom. ${ }^{12}$ However, in most cases the aetiology of AUB in premenopausal women could be a structural cause, such as leiomyoma, adenomyosis, or endometrial or cervical polyps.

AUB can be broadly classified depending on the bleeding pattern as ovulatory or anovulatory bleeding. Anovulatory bleeding refers to irregular or infrequent periods with heavy or light menstrual bleeding, whereas the ovulatory bleeding pattern has regular cycles with normal or increased duration of bleeding. ${ }^{13,14}$ Chronic anovulation due to prolonged unopposed oestrogen stimulation of the endometrium is strongly associated with endometrial hyperplasia/endometrial carcinoma. ${ }^{14}$

Risk stratification of endometrial cancer in postmenopausal women is based on symptoms (postmenopausal bleeding) and transvaginal sonographic estimation of endometrial thickness $(\geq 5 \mathrm{~mm})$. Symptomatic postmenopausal women with endometrial thickness of $\leq 5 \mathrm{~mm}$ are said to have lower endometrial cancer risk (1\%). However, there is no consensus on what the normal endometrial thickness is in premenopausal women or in patients on hormone therapy, apart from the predictive performance of a thick endometrium, which shows conflicting results in the literature. ${ }^{15}$ Moreover, risk stratification using endometrial thickness in premenopausal women with AUB is difficult, leading to the use of other clinical variables.

The evidence on premenopausal AUB and the risk of endometrial cancer remains uncertain and varies. Most of the guidelines suggest an age cut-off above which the patients are at risk of endometrial cancer. This is 40 years in some and 45 years in others. ${ }^{16,17}$ All guidelines recommend biopsy based on several risk factors, such as obesity or polycystic ovary syndrome. The UK National Institute for Health and Care Excellence (NICE) guidelines recommend only biopsy when conventional medical management fails. However, other guidelines recommend direct biopsy in high-risk patients with AUB. ${ }^{17,18}$

The results of large systematic reviews showing lower risk of atypical endometrial hyperplasia (AEH) or endometrial cancer (EC) in premenopausal women with AUB have been questionable. To determine which premenopausal women are at higher risk of premalignant (AEH) and malignant lesions of the uterine endometrium (EC), we sought to form a risk-scoring model using clinical characteristics.

\section{Participants and Methods}

This retrospective cohort study was conducted at a tertiary care hospital after obtaining clearance from Kasturba Medical College and Kasturba Hospital Institutional Ethics Committee (IEC: 597/2019), and included women aged $\leq 55$ years who had undergone endometrial biopsy between June 2014 and August 2019. Patients' consent to review their medical records was not required by the Institutional Review Board as the study was based only on the review of their files. Patient data confidentiality was maintained, and the study was compliant with the Declaration of Helsinki. Women were included if they had a history of AUB diagnosed by the clinician and had not attained menopause (amenorrhea $\geq 12$ months or serum follicle-stimulating hormone levels of $\geq 40 \mathrm{IU} / \mathrm{L}$ ). The flowchart of participants is shown in Figure 1.

Participants were identified from hospital operation database registers and day-care procedure records, including both inpatient and outpatient records. Clinical, demographic and ultrasound data were collected from discharge summary sheets by directly linking with the hospital's electronic medical records. The following information was collected: age, parity, BMI, age of menarche, menstrual history, use of current hormonal drugs, medical history (hypertension, diabetes, and familial cancers such as breast cancer and colorectal cancer) and family history (breast, endometrium and colon cancers). Furthermore, a recent transvaginal ultrasound report was recorded.

With respect to menstrual history, the age of menarche, frequency of menstrual cycle, regularity of menses 


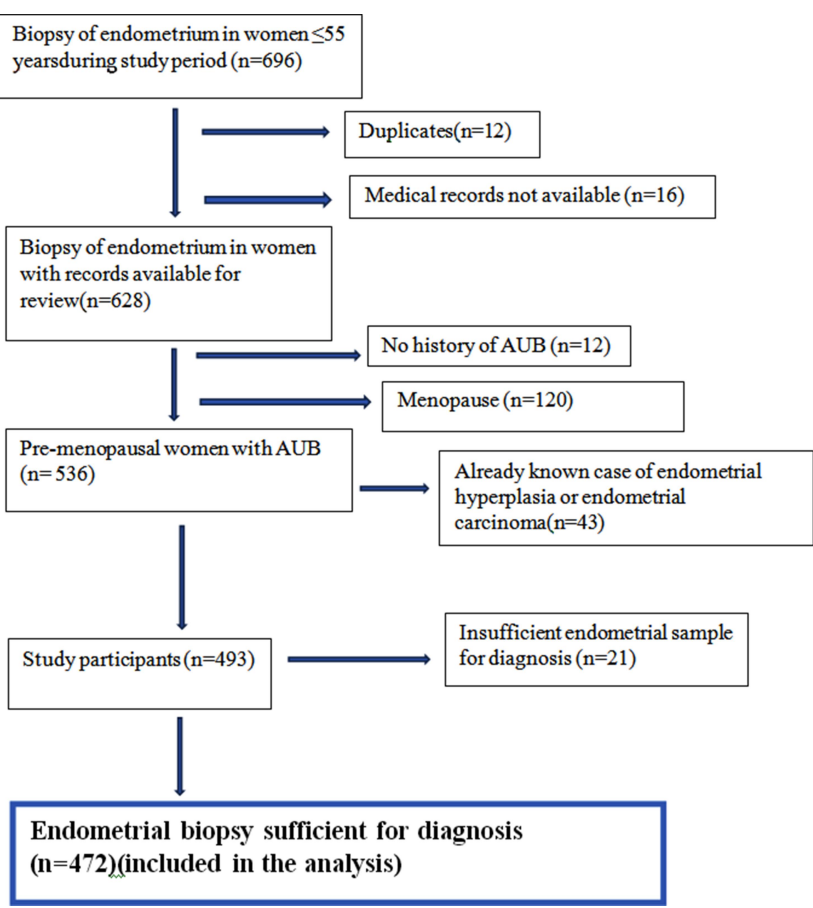

Figure I Flowchart of participants.

(regular/irregular), mean duration of flow and history of intermenstrual bleeding were noted. The menstrual abnormalities were grouped into two types, namely ovulatory and anovulatory bleeding patterns. Anovulatory bleeding is defined as irregular or infrequent periods with heavy or light menstrual bleeding, whereas the ovulatory bleeding pattern has regular cycles with normal or increased duration of bleeding.

Details of the method of endometrial sampling, findings at sampling and histopathology examination (HPE) report were collected. If more than one biopsy was taken from the same participant, then the one with the most serious diagnosis was included as the final result. Primary results were the histological diagnosis of endometrial biopsy of the premalignant lesion (AEH) and malignant lesion (EC) of the uterine endometrium, as stated by the HPE report. Based on the presence of $\mathrm{AEH} / \mathrm{EC}$, the participants were categorised as cases (AEH/EC) and controls (no AEH/EC).

\section{Statistical Analysis}

The overall incidence of AEH and EC in the study participants was determined as numbers and percentages. Clinical and demographic variables among cases (AEH/ EC) and controls (no AEH/EC) were compared using simple logistic regression. The chi-squared test, Fisher's exact test and Mann-Whitney $U$-test were performed where appropriate to evaluate the categorical and continuous variables. Odds ratio (ORs) and $95 \%$ CIs were estimated for each of these variables obtained. A $p$-value of $<0.05$ was considered as statistically significant in all cases. Multivariate logistic regression analysis was performed to assess the independent association between each variable (selecting only patient characteristics) and the outcome (women with histology showing AEH or EC).

According to the predictive OR of every variable acquired in the multivariate analysis, a score was assigned and a risk-scoring model was built to predict AEH/EC among the study participants. ROC curve analysis was accomplished to evaluate the optimal cut-off score for the same. The sensitivity, specificity, positive predictive value (PPV), negative predictive value (NPV), positive likelihood ratio $(\mathrm{LR}+)$ and negative likelihood ratio (LR-) were obtained for each score. The prevalence of AEH/EC in the study participants was considered as the pre-test probability; the post-test probability of AEH/EC was calculated by a series of equations. ${ }^{19}$

To validate the risk-scoring model, we used a splitsample internal validation method. ${ }^{20-22}$ The study population was divided into two groups, maintaining equal numbers of cases with $\mathrm{AEH} / \mathrm{EC}$ in each group. The riskscoring model was first developed in one group (training group) and later checked with the other group (validation group). The stepwise regression model of the training group was evaluated to determine whether it produced the same subset of predictors produced by the regression model of the whole group of study participants. ${ }^{20}$ The coefficient of determination $\left(R^{2}\right)$ between the training and validation groups was compared. If the shrinkage was $\leq 2 \%$, validation was considered significant. ${ }^{23}$ Multiple regression analysis was used to find the $R^{2}$ between the two groups. The final prediction model was derived from the complete derivation sample. ${ }^{20}$ The $R^{2}$ of the training and validation samples was attained by multiple regression analysis.

\section{Results}

A total of 472 women were included in the study and were used in the analysis (Figure 1). Of these, 189 women (40\%) underwent pipelle, 226 (48\%) had sharp endometrial curettage, nine (2\%) had both and $47(10 \%)$ underwent hysteroscopic endometrial biopsy, as the method of endometrial sampling.

Histological examination revealed eight women (1.7\%) with EC, 20 (4.23\%) with AEH, 48 (10.16\%) with simple 
hyperplasia without atypia, 87 (18.4\%) with endometrial polyp, 51 (10.8\%) with pill endometrium (decidualised stroma with widely dispersed atrophic glands due to prolonged exposure to progesterone), 107 (22.6\%) with disordered proliferative endometrium, 135 (28.6\%) with normal secretory endometrium and $16 \quad(3.3 \%)$ with atrophic or inactive endometrium.

A total of 28 women $(6 \%)$ who had AEH or EC were cases and the remaining 444 (94\%) with other endometrial pathology were controls. There were no patients with a history of breast cancer or colorectal cancer. Patient characteristics demonstrated no differences with respect to age at menarche, parity, hypertension, current hormonal therapy or and breast cancer history. Conversely, significant differences were present with regard to age $\geq 45$ years ( $p=0.001)$, history of diabetes $(p=0.001)$, BMI $(p=0.01)$, anovulatory bleeding patterns $(p=0.003)$, endometrial thickness $\geq 12 \mathrm{~mm}$ ( $p=0.001$ ), family history of breast cancer $(p=0.001)$ and family history of colon cancer ( $p=0.001$ ) using univariate analysis (Table 1 ).

A multivariate logistic regression model was used to define the best predictors of $\mathrm{AEH} / \mathrm{EC}$. It indicated that patient's age $\geq 45$ years ( $\mathrm{OR}=1.1,95 \%$ CI $1.0-1.2)$, BMI $\geq 30 \mathrm{~kg} / \mathrm{m}^{2} \quad(\mathrm{OR}=2.46,95 \%$ CI $1.02-5.94$, anovulatory pattern of bleeding $(\mathrm{OR}=3.4 \mathrm{CI}, 1.27-8.94)$ and presence of diabetes $(\mathrm{OR}=3.00,95 \%$ CI $1.28-7.61)$ increased the risk of $\mathrm{AEH} / \mathrm{EC}$ when corrected for other characteristics (Table 2). Since there were only a few cases with a family history of breast cancer $(n=3)$ and colon cancer $(n=1)$, they were not included in the multivariate analysis despite being significant on the univariate analysis.

A split-sampling internal validation method was preformed, and it was observed that the same predictors of the whole study population were produced after stepwise regression of the training group. The coefficient of determination $(R)$ was obtained for the training and validation samples using multiple regression analysis. The shrinkage between the two groups $\left(R^{2}-R^{2}\right)$ was $0.023(\leq 2 \%)$, which meant that the validation was successful.

According to the predictive OR of every variable attained in the multivariate analysis, a score was assigned for every significant predictive factor: age $\geq 45$ years $=1$; anovulatory pattern of bleeding $=3$; presence of diabetes $=3$; BMI $\geq 30 \mathrm{~kg} / \mathrm{m}^{2}=2$. A risk-scoring model called PAD30 was built. The total PAD30 score was evaluated by adding the scores for every clinical characteristic. The maximum and minimum scores were 9 and 0 , respectively.
Subsequently, an ROC curve was built associated with the risk-scoring model. The area under the curve was 0.848 (95\% CI $0.75-0.93 ; p<0.048$ ) (Figure 2). For every score, the sensitivity, specificity, PPV, NPV, LR+ and LRwere reported (Table 3). At the best cut-off value (score $\geq 5$ ), sensitivity and specificity were $85.7 \%$ and $87.6 \%$, respectively; the PPV and NPV were $30.6 \%$ and $98.9 \%$, respectively; LR+ was 6.91 (with a pre-test probability of $6 \%$ and post-test probability of $30.6 \%$ ); and LR- was 0.16 (with a pre-test probability of $6 \%$ and post-test probability of $1.03 \%$ ). A score $\geq 5$ demonstrated a reasonable capacity to discriminate between women with premalignant/malignant lesions (AEH/EC) and those without the disease (no $\mathrm{AEH} / \mathrm{EC})$.

\section{Discussion}

The key risk factors for the progression of $\mathrm{AEH} / \mathrm{EC}$ in premenopausal women with AUB identified in our study and included in our risk-scoring model were: age $\geq 45$ years, anovulatory pattern of bleeding, presence of diabetes mellitus and BMI $\geq 30 \mathrm{~kg} / \mathrm{m}^{2}$. Among these risk factors, anovulatory pattern of bleeding and presence of diabetes mellitus were considered stronger predictors for AEH/EC compared to age $\geq 45$ years and BMI $\geq 30 \mathrm{~kg} / \mathrm{m}^{2}$ (or obesity), and thus, were awarded a higher weighting in our risk-scoring model. We proposed using a PAD30 score $\geq 5$ as the cut-off for the identification of women at high risk of AEH/EC. The newly proposed model showed good sensitivity and specificity of $85.7 \%$ and $87.6 \%$, respectively, when tested on the control sample. The PPV and NPV for the model were determined to be $30.6 \%$ and $98.9 \%$, respectively, with an LR+ of 6.91 (a pre-test probability of $6 \%$ and post-test probability of $30.6 \%$ ) and LR- of 0.16 (a pre-test probability of $11.5 \%$ and post-test probability of $1.03 \%$ ). These values indicate that the proposed model can reliably be used to identify premenopausal women with AUB who are at high risk of $\mathrm{AEH} / \mathrm{EC}$ even in primary care settings, without the need for laboratory/imaging examination. This will help in avoiding unnecessary sampling/biopsy in this population and could save a lot of resources. Thus, the risk model is a win-win approach for both patients and healthcare providers.

The incidence of $\mathrm{AEH} / \mathrm{EC}$ reported in our study (ie, $6 \%$ ) is higher than the results reported by other researchers $^{11}$ and in a systematic review of the literature. ${ }^{24}$ This is because we conducted this study at 
Table I Univariate Analysis of Demographic and Clinical Characteristics Associated with Atypical Endometrial Hyperplasia and/or Endometrial Cancer (AEH/EC)

\begin{tabular}{|c|c|c|c|c|}
\hline \multirow[t]{2}{*}{ Risk Factors } & \multirow{2}{*}{$\begin{array}{l}\text { Women with AEH/EC } \\
(n=28)(6 \%)\end{array}$} & Women Without AEH/EC & \multirow[t]{2}{*}{ OR $(95 \% \mathrm{Cl})$} & \multirow[t]{2}{*}{$p$ Value } \\
\hline & & $(n=444)(94 \%)$ & & \\
\hline Age (years)* & $45(40-49)$ & $41(37-45)$ & $1.12(1.02-1.21)$ & $0.001^{\mathrm{a}}$ \\
\hline Age at menarche (years)* & $12(10-14)$ & $11(11-13)$ & $1.2(0.4-1.8)$ & $0.29^{\mathrm{a}}$ \\
\hline Duration of AUB (months)* & $12(6-18)$ & $6(4-12)$ & $1.3(0.3-1.2)$ & $0.01^{\mathrm{a}}$ \\
\hline Endometrial thickness $(\mathrm{mm})^{*}$ & $12(9-16)$ & $8(6-10)$ & $2.1(1.4-2.45)$ & $0.001^{\mathrm{a}}$ \\
\hline \multicolumn{5}{|l|}{ BMI $\left(\mathrm{kg} / \mathrm{m}^{2}\right)^{*}$} \\
\hline$<30$ & $17(60.7 \%)$ & $385(86.7 \%)$ & 1.00 & $0.001^{\mathrm{b}}$ \\
\hline$\geq 30$ & $11(39.3 \%)$ & $59(13.3 \%)$ & $4.22(1.88-9.45)$ & \\
\hline \multicolumn{5}{|l|}{ Parity } \\
\hline Multiparity & $22(82.2 \%)$ & $376(79 \%)$ & 1.00 & $0.8^{\mathrm{b}}$ \\
\hline Nulliparity & $6(17 \%)$ & $68(21.15 \%)$ & $2.11(0.63-3.24)$ & \\
\hline \multicolumn{5}{|l|}{ Current hormonal therapy } \\
\hline No & $22(78.6 \%)$ & $315(70.9 \%)$ & 1.00 & $0.3^{\mathrm{b}}$ \\
\hline Yes & $6(21.4 \%)$ & $129(29.1 \%)$ & $0.9(0.45-1.75)$ & \\
\hline \multicolumn{5}{|l|}{ Menstrual cycle regularity } \\
\hline Regular & $8(28.6 \%)$ & $204(45.9 \%)$ & 1.00 & $0.08^{\mathrm{b}}$ \\
\hline Irregular & 20 (7I.4\%) & $240(54.1 \%)$ & $1.58(0.78-3.21)$ & \\
\hline \multicolumn{5}{|l|}{ Duration of menstrual cycle } \\
\hline$<7$ days & $7(25 \%)$ & $78(25 \%)$ & 1.00 & \\
\hline $7-14$ days & $14(50 \%)$ & $307(69.1 \%)$ & $0.55(0.18-1.65)$ & $0.07^{c}$ \\
\hline$>14$ days & $7(25 \%)$ & $59(13.3 \%)$ & $1.37(0.58-3.25)$ & \\
\hline \multicolumn{5}{|l|}{ Intermenstrual bleeding } \\
\hline No & $24(85.7 \%)$ & $390(87.8 \%)$ & 1.00 & $0.53^{\mathrm{b}}$ \\
\hline Yes & $4(14.3 \%)$ & $54(12.2 \%)$ & $0.64(0.28-1.48)$ & \\
\hline \multicolumn{5}{|l|}{ Frequency of menstrual cycle } \\
\hline More frequent (once in $<2$ I days) & $7(25 \%)$ & $78(25 \%)$ & $0.55(0.18-1.65)$ & \\
\hline Normal frequency (once in $21-35$ days) & $14(50 \%)$ & $307(69.1 \%)$ & 1.00 & $0.08^{\mathrm{c}}$ \\
\hline Less frequent (once in $>35$ days) & $7(25 \%)$ & $59(13.3 \%)$ & $1.37(0.58-3.25)$ & \\
\hline \multicolumn{5}{|l|}{ Bleeding pattern* } \\
\hline Ovulatory bleeding & $6(21.4 \%)$ & $235(52.9 \%)$ & 1.00 & $0.003^{\mathrm{b}}$ \\
\hline Anovulatory bleeding & $22(78.6 \%)$ & $209(47.1 \%)$ & $4.12(1.64-10.36)$ & \\
\hline \multicolumn{5}{|l|}{ Diabetes* } \\
\hline No & $19(67.9 \%)$ & $402(90.5 \%)$ & 1.00 & $0.001^{\mathrm{b}}$ \\
\hline Yes & $9(32.1 \%)$ & $42(9.5 \%)$ & $4.53(1.92-10.65)$ & \\
\hline \multicolumn{5}{|l|}{ Hypertension } \\
\hline No & $23(82.6 \%)$ & $337(77.1 \%)$ & 1.00 & $0.2^{\mathrm{b}}$ \\
\hline Yes & $5(21.4 \%)$ & $106(23.9 \%)$ & $0.54(0.19-1.57)$ & \\
\hline \multicolumn{5}{|l|}{ Family history of breast cancer* } \\
\hline No & $26(92.8 \%)$ & 47 ( $99.8 \%)$ & 1.00 & $0.001^{\mathrm{b}}$ \\
\hline Yes & $2(7.14 \%)$ & $\mathrm{I}(0.2 \%)$ & $2.111(0.72-6.18)$ & \\
\hline \multicolumn{5}{|l|}{ Family history of colon cancer* } \\
\hline No & 27 (97.5\%) & $444(100 \%)$ & - & $0.001^{\mathrm{b}}$ \\
\hline Yes & I (3.5\%) & $0(0)$ & & \\
\hline
\end{tabular}

Notes: Values are expressed as median and interquartile range (IQR). ${ }^{\mathrm{T}}$ Two-sampled Wilcoxon rank sum test (Mann-Whitney U-test), ${ }^{\mathrm{b}}$ chi-squared test, ${ }^{\mathrm{c}}$ Fisher's exact test. Anovulatory bleeding includes irregular or infrequent cycles with prolonged bleeding ( $>7$ days); ovulatory bleeding includes regular cycles with heavy bleeding. *Statistically significant findings.

Abbreviations: AUB, abnormal uterine bleeding; $\mathrm{BMI}$, body mass index; OR, odds ratio; $\mathrm{Cl}$, confidence interval. 
Table 2 Multivariate Regression Analysis Showing Clinical Characteristics for Prediction of AEH/EC

\begin{tabular}{|l|l|l|l|l|}
\hline Variables & OR & $\mathbf{9 5 \%} \mathbf{~ C l}$ & Criterion & $\mathbf{P}$ Value \\
\hline Age & 1.12 & $1.02-1.21$ & $\geq 45$ years & 0.01 \\
Anovulatory pattern of & 3.4 & $1.27-8.94$ & - & 0.009 \\
bleeding & & & & \\
BMI $\geq 30 \mathrm{~kg} / \mathrm{m}^{2}$ & 2.46 & $1.02-5.94$ & & 0.04 \\
Diabetes = yes & 3.00 & $1.28-7.6 \mathrm{I}$ & & 0.02 \\
\hline
\end{tabular}

Note: Using stepwise regression analysis, variables not included in the model: duration of $A U B$, endometrial thickness, family history of breast carcinoma, family history of colon cancer, which showed significant association in univariate analysis. Abbreviations: OR, odds ratio; $\mathrm{Cl}$, confidence interval; $\mathrm{BMI}$, body mass index.

a tertiary hospital, which deals with most of the referred cases from the primary healthcare centres. Thus, the current study participants were already at a higher risk of developing $\mathrm{AEH} / \mathrm{EC}$ and a higher incidence could thus be justified. We found a statistically significant positive correlation of anovulatory pattern of bleeding and the presence of diabetes mellitus with a higher risk of $\mathrm{AEH} /$ EC development/diagnosis in the study participants. The results are in line with the results reported by other researchers. ${ }^{25,26}$ Based on our results, we considered age as a predictor of $\mathrm{AEH} / \mathrm{EC}$ risk in the study population; however, similar results were not obtained by all the previous analyses carried out to explore this association. Some researchers reported no association while others reported a statistically significant positive correlation between age and the risk of AEH/EC. ${ }^{25-27}$ Iram et $\mathrm{al}^{28}$

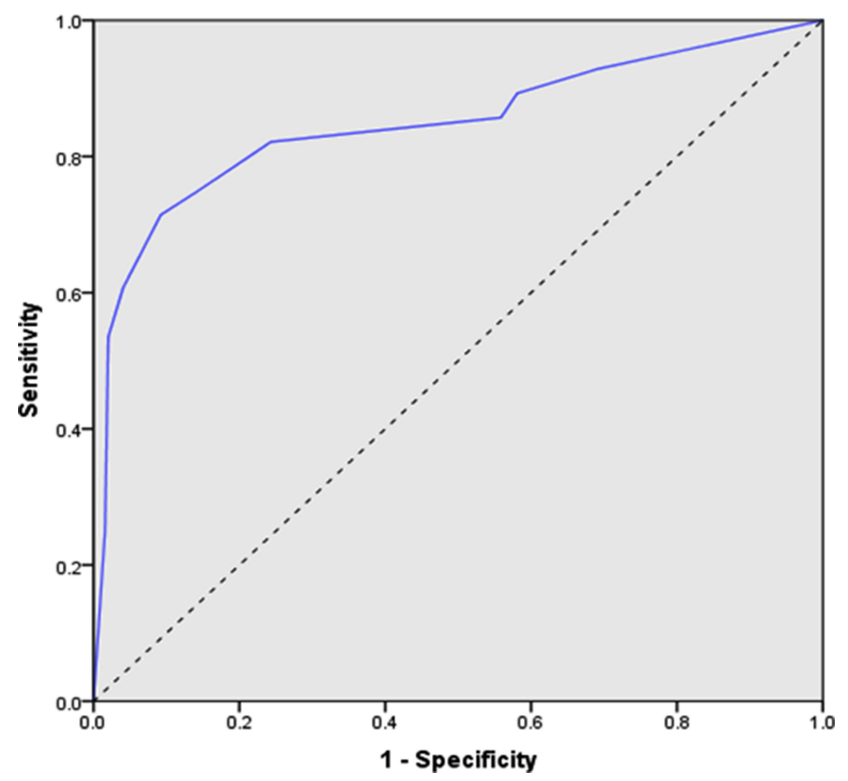

Figure 2 Receiver operating characteristics curve for the risk-scoring model PAD30, with an area under the curve (AUC) of 0.848 (95\% Cl 0.75-0.93; $p<0.048)$. reported that the risk of $\mathrm{AEH} / \mathrm{EC}$ is higher in women with an age of $>45$ years. However, a history of irregular menstrual bleeding itself is an indication to investigate women, regardless of their age. Obesity or higher BMI was another risk factor for the development of $\mathrm{AEH} / \mathrm{EC}$ identified in the current study. This is consistent with most of the previously reported results by other researchers. $^{14,25,29,30}$

The endometrial thickness is another risk factor for the development of $\mathrm{AEH} / \mathrm{EC}$, as reported by several researchers. ${ }^{29-34}$ However, the relevance of this risk factor in premenopausal women remains debatable because of a continuous change in the endometrial thickness in this population owing to periodic menstrual phases. In the present study, we included only patient clinical characteristics (excluding transvaginal sonographic assessment of endometrial thickness) to build a risk-scoring model, thus we did not include thick endometrium in the model. Similarly, some other risk factors reported by other researchers were not included in our risk model based on their non-significance observed in our study, for example, reproductive history, parity, hypertension, hormone use and smoking. ${ }^{35}$

The requirement of endometrial biopsy in premenopausal women with AUB is not clearly indicated by different guidelines. Some guidelines recommend endometrial biopsy in women with age $>40$ years and in all women with comorbidities. ${ }^{16,35}$ However, the NICE guidelines recommend endometrial biopsy only after the failure of medical treatment for AUB. ${ }^{17}$ In addition, coherent recommendations are not available in the literature regarding the requirement for endometrial biopsy in this population. ${ }^{25-28}$ The current study, however, provides a risk model as a reliable tool to distinguish clearly the high-risk individuals who require endometrial biopsy or further investigations. Based on the previous various recommendations and present study results, we propose a management pathway for premenopausal women with abnormal uterine bleeding (Figure 3)

The risk model (PAD30) proposed in the current study was successfully validated using internal reference standards, and desirable sensitivity, specificity, PPV, NPV, LR+ and LR- values were obtained. Subjects with missing data were not included in the study, and both univariate and multivariate analyses were conducted to determine important risk factors which only included patient characteristics. Those requiring laboratory/imaging analysis were excluded. 
Table 3 Sensitivity, Specificity, PPV, NPV, LR+, LR-, Pre- and Post-Test Probability for Each Score of Our Risk-Scoring Model

\begin{tabular}{|c|c|c|c|c|c|c|c|c|}
\hline $\begin{array}{l}\text { Cut-Off } \\
\text { Score }\end{array}$ & Sensitivity (\%) & Specificity (\%) & PPV (\%) & NPV (\%) & LR+ & LR- & $\begin{array}{l}\text { Pre-Test } \\
\text { Probability (\%) }\end{array}$ & $\begin{array}{l}\text { Post-Test } \\
\text { Probability (\%) }\end{array}$ \\
\hline$\geq 0$ & 100 & 0 & 6 & - & - & - & 6 & 0 \\
\hline$\geq 1$ & 100 & 33.1 & 8.7 & 100 & - & 0 & 6 & 0 \\
\hline$\geq 2$ & 100 & 44.4 & 10.2 & 100 & - & 0 & 6 & 0 \\
\hline$\geq 3$ & 96.4 & 46.6 & 10.3 & 99.5 & - & 0.07 & 6 & 0.4 \\
\hline$\geq 4$ & 92.9 & 78.2 & 21.3 & 99.4 & - & 0.09 & 6 & 0.5 \\
\hline$\geq 5$ & 85.7 & 87.6 & 30.6 & 98.9 & - & 0.16 & 6 & 1.03 \\
\hline$\geq 6$ & 82.1 & 91.9 & 39.2 & 98.7 & - & 0.19 & 6 & 1.22 \\
\hline$\geq 7$ & 64.3 & 96.6 & 54.6 & 97.6 & - & 0.36 & 6 & 2.3 \\
\hline$\geq 8$ & 53.6 & 98.2 & 65.5 & 97.07 & - & 0.47 & 6 & 2.92 \\
\hline$\geq 9$ & 25 & 98.6 & 53.2 & 95.36 & - & 0.76 & 6 & 4.6 \\
\hline$>9$ & 0 & 100 & - & 94 & - & I & 6 & 6 \\
\hline- & - & - & - & - & - & - & - & - \\
\hline$\geq 0$ & 100 & 0 & 6 & - & I & - & 6 & 6 \\
\hline$\geq 1$ & 100 & 33.1 & 8.7 & 100 & 1.49 & - & 6 & 8.7 \\
\hline$\geq 2$ & 100 & 44.4 & 10.2 & 100 & 1.79 & - & 6 & 10.2 \\
\hline$\geq 3$ & 96.4 & 46.6 & 10.3 & 99.5 & 1.80 & - & 6 & 10.3 \\
\hline$\geq 4$ & 92.9 & 78.2 & 21.3 & 99.4 & 4.26 & - & 6 & 21.3 \\
\hline$\geq 5$ & 85.7 & 87.6 & 30.6 & 98.9 & 6.91 & - & 6 & 30.6 \\
\hline$\geq 6$ & 82.1 & 91.9 & 39.2 & 98.7 & 10.13 & - & 6 & 39.2 \\
\hline$\geq 7$ & 64.3 & 96.6 & 54.6 & 97.6 & 18.91 & - & 6 & 54.6 \\
\hline$\geq 8$ & 53.6 & 98.2 & 65.5 & 97.07 & 29.77 & - & 6 & 65.5 \\
\hline$\geq 9$ & 25 & 98.6 & 53.2 & 95.36 & 17.85 & - & 6 & 53.2 \\
\hline$>9$ & 0 & 100 & - & 94 & - & - & 6 & 0 \\
\hline
\end{tabular}

Note: Values highlighted in bold indicate the intersection of the sensitivity and specificity curves against the cut-off mentioned.

Thus, the proposed risk model can unarguably be considered a better model for AEH/EC risk assessment in primary healthcare settings compared to previously reported risk models. ${ }^{30}$ A systematic review compared the previously reported risk models and highlighted several limitations of these risk models. ${ }^{35,36}$

\section{Applications and Drawbacks of the Current Study}

The present study is the first of its kind to introduce a reliable risk-scoring model for predicting premalignant and malignant lesions of the uterine endometrium among symptomatic premenopausal women using only patient characteristics, without incorporating laboratory/ imaging examination findings. The capability to offer risk assessment without the necessity for any laboratory and imaging examinations would permit such an assessment to be accomplished in a primary care setting. However, the current study does have certain limitations. First, it was a retrospective analysis and the results were not validated using a prospective sample and no external reference was used. Secondly, no genetic, epigenetic or biomarker indicators were included in our risk-model development, which could have furnished better accuracy. However, considering the objective of implementing the riskmodel in a primary care setting, this limitation can be overlooked easily. Finally, the proposed riskmodel could not be validated for geographically and temporally different populations.

\section{Conclusion}

The proposed risk-scoring model demonstrated a moderate diagnostic accuracy in predicting premalignant and malignant lesions of the uterine endometrium among symptomatic premenopausal women. These data would allow the clinician to decide the management approach for premenopausal women with AUB. In future, advanced investigation is essential to externally confirm the predictive model established in high-risk populations (with a family history of breast and colorectal cancer) to evaluate its clinical relevance. 

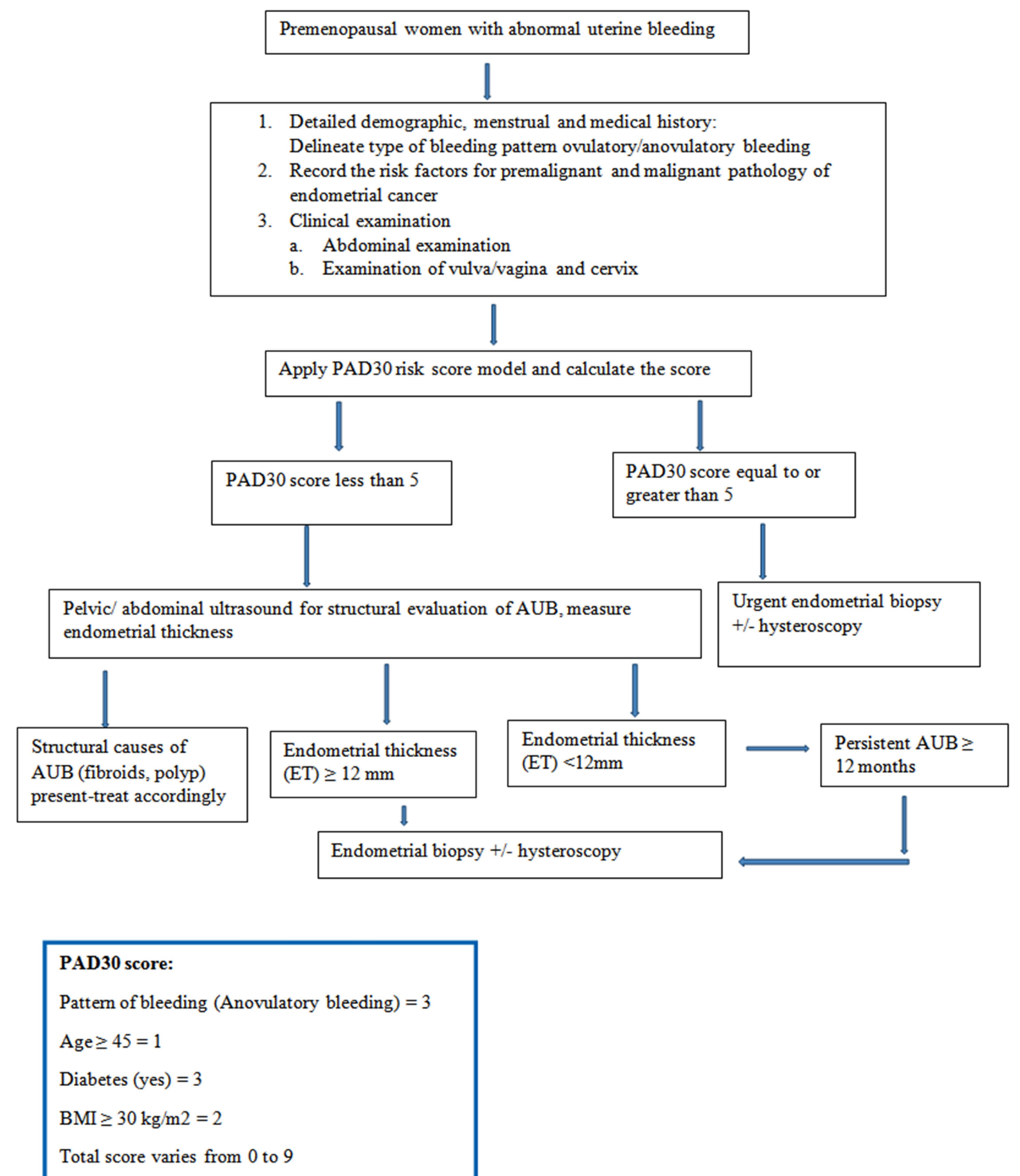

Figure 3 Risk assessment pathway for management of premenopausal women with abnormal uterine bleeding.

\section{Funding}

There is no funding to report.

\section{Disclosure}

The authors report no conflicts of interest in this work.

\section{References}

1. Bray F, Ferlay J, Soerjomataram I, et al. Global cancer statistics 2018: GLOBOCAN estimates of incidence and mortality worldwide for 36 cancers in 185 countries. CA Cancer J Clin. 2018;68(6):394-424.

2. Uterine Cancer: Statistics. Available from: https://www.cancer.net/can cer-types/uterine-cancer/statistics. Accessed September 30, 2020.

3. Lacey JV, Ioffe OB, Ronnett BM, et al. Endometrial carcinoma risk among women diagnosed with endometrial hyperplasia: the 34-year experience in a large health plan. Br J Cancer. 2008;98(1):45-53.
4. Sobczuk K, Sobczuk A. New classification system of endometrial hyperplasia WHO 2014 and its clinical implications. Prz Menopauzalny. 2017;16(3):107-111. doi:doi:10.5114/pm.2017.70589

5. Trimble CL, Kauderer J, Zaino R, et al. Concurrent endometrial carcinoma in women with a biopsy diagnosis of atypical endometrial hyperplasia: a Gynecologic Oncology Group study. Cancer. 2006;106 (4):812-819. doi:10.1002/cncr.21650

6. Constantine GD, Kessler G, Graham S, Goldstein SR. Increased incidence of endometrial cancer following the women's health initiative: an assessment of risk factors. $J$ Womens Health (Larchmt). 2019;28 (2):237-243. doi:10.1089/jwh.2018.6956

7. Cote ML, Ruterbusch JJ, Olson SH, et al. The growing burden of endometrial cancer: a major racial disparity affecting black women. Cancer Epidemiol Biomarkers Prev. 2015;24(9):1407-1415. doi:10.1158/1055-9965.EPI-15-0316

8. Renehan AG, Soerjomataram I, Tyson M, et al. Incident cancer burden attributable to excess body mass index in 30 European countries. Int $J$ Cancer. 2010;126(3):692-702. doi:10.1002/ijc.24803

9. Ferlay J, Soerjomataram I, Dikshit R, et al. Cancer incidence and mortality worldwide: sources, methods and major patterns in GLOBOCAN 2012. Int J Cancer. 2015;136(5):E359-86. doi:10.1002/ijc.29210 
10. Wise MR, Jordan V, Lagas A, et al. Obesity and endometrial hyperplasia and cancer in premenopausal women: a systematic review. $\mathrm{Am}$ J Obstet Gynecol. 2016;214(6):689.e1-e17.

11. Farquhar CM, Lethaby A, Sowter M, Verry J, Baranyai J. An evaluation of risk factors for endometrial hyperplasia in premenopausal women with abnormal menstrual bleeding. Am J Obstet Gynecol. 1999;181(3):525-529. doi:10.1016/S0002-9378(99)70487-4

12. Early detection, diagnosis and staging of endometrial cancer. Available from: https://www.cancer.org/cancer/endometrial-cancer /detection-diagnosis-staging/signs-and-symptoms.html. Accessed September 30, 2020.

13. ACOG Committee on Practice Bulletins-Gynecology. American College of Obstetricians and Gynecologists. ACOG Practice Bulletin: management of anovulatory bleeding. Int $J$ Gynaecol Obstet. 2001;72(3):263-271.

14. Sweet MG, Schmidt-Dalton TA, Weiss PM, Madsen KP. Evaluation and management of abnormal uterine bleeding in premenopausal women. Am Fam Physician. 2012;85(1):35-43.

15. Disaia P, Creasman W. Adenocarcinoma of the Uterus. Clinical Gynecologic Oncology. 7th ed. 2007:147-184.

16. Royal College of Obstetricians and Gynaecologists. Standards for Gynaecology: Report of a Working Party. London. 2008 June; 1-56.

17. National Institute for Health and Clinical Excellence. Heavy Menstrual Bleeding: Assessment and Management. NICE Guideline; 2018.

18. American College of Obstetricians and Gynecologists. Diagnosis of abnormal uterine bleeding in reproductive-aged women. Pract Bull. 2012;128:197-206.

19. Gardner IA, Greiner M. Receiver-operating characteristic curves and likelihood ratios: improvements over traditional methods for the evaluation and application of veterinary clinical pathology tests. Vet Clin Pathol. 2006;35(1):8-17. doi:10.1111/j.1939-165X.2006. tb00082.x

20. Wiegand RE. Performance of using multiple stepwise algorithms for variable selection. Stat Med. 2010;29(15):1647-1659.

21. Wang D, Zhang W, Bakhai A. Comparison of Bayesian model averaging and stepwise methods for model selection in logistic regression. Stat Med. 2004;23(22):3451-3467. doi:10.1002/sim.1930

22. Labarère J, Bertrand R, Fine MJ. How to derive and validate clinical prediction models for use in intensive care medicine. Intensive Care Med. 2014;40(4):513-527. doi:10.1007/s00134-014-3227-6

23. Osborne JW. Prediction in multiple regression. Pract Assessment Res Eval. 2000;7:2. doi:10.7275/7j20-gg86

24. Pennant ME, Mehta R, Moody P, et al. Premenopausal abnormal uterine bleeding and risk of endometrial cancer. BJOG. 2017;124 (3):404-411. doi:10.1111/1471-0528.14385

25. Guraslan H, Dogan K, Kaya C, et al. Could body mass index be an indicator for endometrial biopsy in premenopausal women with heavy menstrual bleeding? Arch Gynecol Obstet. 2016;294 (2):395-402. doi:10.1007/s00404-016-4043-8
26. Corbacioglu Esmer O, Akbayir BPC, Goksedef, et al. Is there an appropriate cutoff age for sampling the endometrium in premenopausal bleeding? Gynecol Obstet Invest. 2014;77(1):40-44. doi:10.1159/ 000356959

27. Gawron ML, Babczyk D, et al. Endometrial cancer and hyperplasia rate in women before menopause with abnormal uterine bleeding undergoing endometrial sampling. Przegl Lek. 2017;74(4):139-143.

28. Iram S, Musonda P, Ewies AA. Premenopausal bleeding: when should the endometrium be investigated? - a retrospective noncomparative study of 3006 women. Eur J Obstet Gynecol Reprod Biol. 2010;148(1):86-89. doi:10.1016/j.ejogrb.2009.09.023

29. Wise MR, Gill P, Lensen S, Tompson JMD, Farquhar CM. Body mass index trumps age in decision for endometrial biopsy: cohort study of symptomatic premenopausal women. Am J Obstet Gynecol. 2016;215(5):598-598.e8. doi:10.1016/j.ajog.2016.06.006

30. Giannella L, Cerami LB, Setti T, Bergamini E, Boselli F. Prediction of endometrial hyperplasia and cancer among premenopausal women with abnormal uterine bleeding. Biomed Res Int. 2019;2019:1-6. doi:10.1155/2019/8598152

31. Ozdemir S, Celik C, Gezginc K, Kiresi D, Esen H. Evaluation of endometrial thickness with transvaginal ultrasonography and histopathology in premenopausal women with abnormal vaginal bleeding. Arch Obstet Gynecol. 2010;282(4):395-399. doi:10.1007/s00404009-1290-y

32. Getpook C, Wattanakumtornkul S. Endometrial thickness screening in premenopausal women with abnormal uterine bleeding. $J$ Obstet Gynaecol Res. 2006;32(6):588-592. doi:10.1111/j.1447-0756.20 06.00455.x

33. Kim M, Kim J, Kim SM. Endometrial evaluation with transvaginal ultrasonography for the screening of endometrial hyperplasia or cancer in premenopausal and perimenopausal women. Obstet Gynecol Sci. 2016;59(3):192. doi:10.5468/ogs.2016.59.3.192

34. Van den Bosch T, Ameye L, Van Schoubroeck D, Bourne T, Timmerman D. Intra-cavitary uterine pathology in women with abnormal uterine bleeding: a prospective study of 1220 women. Facts Views Vis Obgyn. 2015;7(1):17-24.

35. Alblasa M, Velta KB, Pashayanb N, Widschwendterc M, Steyerberga EW, Yvonne V. Prediction models for endometrial cancer for the general population or symptomatic women: A systematic review. Crit Rev Oncol Hematol. 2018;126:92-99. doi:10.1016/j. critrevonc.2018.03.023

36. Kitson SJ, Evans DG, Crosbie EJ. Identifying high-risk women for endometrial cancer prevention strategies: proposal of an endometrial cancer risk prediction model. Cancer Prev Res (Phila). 2017;10 (1):1-13. doi:10.1158/1940-6207.CAPR-16-0224.

\section{Publish your work in this journal}

The International Journal of Women's Health is an international, peerreviewed open-access journal publishing original research, reports, editorials, reviews and commentaries on all aspects of women's healthcare including gynecology, obstetrics, and breast cancer. The manuscript management system is completely online and includes a very quick and fair peer-review system, which is all easy to use. Visit http://www.dovepress.com/testimonials.php to read real quotes from published authors. 